\title{
The Empirical Study of the Effect of Multi-Feedback on Self-Efficacy Sense of College English Writing
}

\author{
Jie Chen ${ }^{1, a}$ \\ ${ }^{1}$ Xi'an Fanyi University, Xi'an, 710105 \\ ${ }^{a}$ email
}

Keywords: Multiple Feedback, College English Writing, Self-Efficacy

\begin{abstract}
With optimization reform of higher education system, the feedback has been gotten more and more interest and research from teachers. Take network technology as the basis, the teacher feedback, peer feedback, verbal feedback and written feedback are combined together and gradually replace the traditional single written feedback. In College Students' writing self-efficacy influence above it plays an important role. This paper can be combined with practical teaching experience to play a role in the expansion of pluralistic feedback empirical research.
\end{abstract}

\section{Introduction}

Writing is an important part of language learning. Is a manifestation of the comprehensive ability to use language learners knowledge, and therefore it is for our students, English writing is more difficult to break through the bottleneck of the project, classroom effect was not significant. Among them, writing feedback as a key link in the smooth implementation of the process of teaching English can help students understand the error in time, constantly revised and progress, a sense of self-efficacy of college English writing has a greater impact. Therefore, teachers should break the routine traditional teacher-based evaluation methods, focusing on the combination of a variety of feedback, so as to further promote students' self-cognitive abilities, through closer communication between teachers and students between life and life, earnestly to improve students' English language literacy.

\section{Background and Summary of Research}

Into the late 20th century, the theory of educational psychology research based on displays, emotional psychology is one of the important factors affecting the motivation of learners and learning efficiency. Positive mental attitude can effectively stimulate the enthusiasm of learners, giving learners more learning fun, otherwise inhibit the learner's enthusiasm, impede learning progress. Wherein the self-efficacy focuses on self-regulation is an important aspect of the impact. For college students, self-efficacy is held by students on their own mission to be engaged and look forward to some preset psychological estimated during the task to complete the task on their own have the ability and confidence to complete the task of judgment and understanding. Thus, self-efficacy determines the level of students to complete the task and the effort to some extent. It has important implications for the behavior of the student learning process control and regulation. Specific impact is reflected in setting learning goals, learning to take and use means of learning strategies. In recent years, many domestic and foreign researchers on self-efficacy for academic activities and impact learners do a useful exploration. Some students find a sense of self-efficacy in grades, the difference more obvious aspects of professional categories, but gender and level of education, etc., but do not see a substantial impact (Wu Yuhong, 2013) [1]; as well as self-efficacy studies have shown feeling of use and learning strategies, activities, feedback and learning behavior have close contact relationship, and learning efficacy can predict academic motivation and academic achievement (Rollinson, 2005; Xia Tianqiong 2014) [2-3]; feelings of self-efficacy learning objectives impact of background variables (Li Hang, Liu Rude, 2013).

The emotional cognitive activity Writing in nature and require sustained training. If the student self-efficacy is good, we will be willing to grasp the logic of English writing and insisted attitude. 
Thus enhancing the University Writing self-efficacy, we must introduce real objective evaluation feedback system in the classroom. This conclusion views and Tang Fang, Xujin Fen (2011) study is consistent with [4]. In the self-efficacy research found that Chinese non English Majors Writing self-efficacy in the middle level on the whole; college English writing and writing self-efficacy scores were moderately correlated. At home and abroad there are a lot of feedback on English studies and related investigations. Diversity refers to the various forms of feedback form contents can be divided into verbal feedback and written feedback; feedback according to different sources into teacher feedback, peer review feedback, self-feedback (Fengjia Yao, 2012 ) [5]; with the widespread use of scientific and technical information, the teaching of writing appeared in Internet applications based "record screen feedback 'study, meaning that teachers use computers for students to carry out evaluation and feedback activities, students also receiving such a combination of sound and image feedback through the internet video platform, to achieve anytime, anywhere communication and exchanges with teachers. Foreign scholars Wang, S. (2008) [6] on this screen recording feedback system with the traditional written for feedback were compared survey showed that teachers use screen recording feedback effects and written feedback on student learning efficiency was superior. Because the form of new and lively students' relatively high degree of acceptance, self-efficacy has been improved.

\section{Study Design and experimental operation}

Design of Multi-Feedback Form. Teacher feedback: include a feedback screen recording and written feedback. In short, it can be made in writing and networking platform for students writing the manuscript feedback. Especially for students writing ideation feedback, so as to promote students better express thoughts and feelings and impressions; additional teachers can make use of Tencent platform in the after-school students in a timely manner in writing appearing in answering questions and doubts.

Peer Feedback: includes group feedback, written feedback and verbal feedback. After the completion of writing, teachers can design according to the specific learning situation "writing peer assessment form", and then divided into groups of students, for students to assess their own Combining indicators and peer assessment table companions expand mutual feedback mechanism. Mutual feedback inspection process can thereby discover their weaknesses and shortcomings exist in the article, writing and drawing highlights companion of expression.

Study of the operation tool. In reference to some of the information and documents, such as the Ministry of Education issued "College English Curriculum Requirements" Annex Writing since the rating scale, this study was designed according to the actual situation, "College English Writing Self - Efficacy Scale", in addition to the "peer feedback" among the "peer review writing table" (shown below in table 1). Before the formal implementation of the experiment, in order to ensure effective scientific results directly reflect the results of the scale has been tested to meet the requirements of statistics. Test data show that the scale has good construct validity, used for the analysis of the experiment is to improve. 
Table 1 Writing assessment table

\begin{tabular}{|l|l|l|}
\hline Columns & evaluation standard & Score (10) \\
\hline \multirow{4}{*}{ Contend } & 1.Article comply with the spirit & \\
\cline { 2 - 3 } & 2.arguments sufficiently powerful & \\
\cline { 2 - 3 } & 3.The central idea of projecting & \\
\hline \multirow{5}{*}{$\begin{array}{l}\text { Language } \\
\text { Expression }\end{array}$} & $\begin{array}{l}\text { 1. reasonable structure, clear thinking } \\
\text { properly transition cohesion, coherence }\end{array}$ & \\
\cline { 2 - 3 } & $\begin{array}{l}\text { 1. words, punctuation, person, tense, and } \\
\text { so correct }\end{array}$ & \\
\cline { 2 - 3 } & 2. The words, phrases properly use correct & \\
\cline { 2 - 3 } & $\begin{array}{l}\text { 3. The sentence is correct and in line with } \\
\text { the structure of English expression habit }\end{array}$ & \\
\hline & Highlights & \\
\cline { 2 - 4 } & insufficient & \\
\hline Suggest & Provide practical advice & \\
\hline
\end{tabular}

Subjects: The present College (College) non-English major freshmen selected 120 were divided into experimental and control groups. The experimental group is 60 people (32 boys, 28 girls), a control group of 60 people (35 boys, 25 girls). Gender experimental and control groups, the age difference was not statistically significant, and the level of English writing can be seen as no different from comparable.

Design of Experiment. The experimental group was divided into several groups, each in accordance with the five or six people in the distribution arrangements. Mode uses a peer review peer feedback, peer assessment Reference List 2 "writing peer assessment Table"; two hours were each lesson of 45 minutes. This set of experiments is expected to be achieved are: (1) give students a clear peer review is an effective Improve Writing Skill manner; (2) objective, to improve self-efficacy of college English writing has a role to help; (3) communicate with each other and exchange between peers is always implement peer feedback link.

The specific implementation process: the experimental group of students to carry out practical activities once every two weeks peer feedback period of three months, or 6 times. After the two groups were the same completed writing assignments, teachers to students in the experimental group using peer reviewers secondary teacher feedback manner. While the control group using the traditional way of teacher feedback, that is in the classroom site review and modify operations. Whether the control group or the experimental group, we need to be clear that the task of writing teachers should be arranged to maintain the same number of words on the requirements and contents.

Before the start of the experiment and after the end of the experiment (reaches a predetermined period, that is, three months later), twice issuing "English writing self-efficacy scale" to the students, and the comparison of the two sets of experiments based on professional statistical software The results were analyzed and studied.

\section{Data Collection and Analysis}

Before start of the test to the student grant "College English Writing Efficacy Scale" verification of students in the experimental group and control group if there are differences in terms of self-efficacy greater extent. The results showed no significant difference between the two, 52.242 and 53.163 respectively, they are in the range of medium level. Similarly, in order to understand peer feedback on the effect of self-efficacy of college English writing, analysis of data shows that the second scale, and found significant differences. $(\mathrm{P}<0.05)$, $\mathrm{t}$ is independent sample. 


\begin{tabular}{|l|l|l|l|l|l|l|}
\hline \multirow{2}{*}{$\begin{array}{l}\text { High } \\
\text { Level } \\
\text { Group }\end{array}$} & Group & $\mathrm{N}$ & Mean & SD & t & Sig. \\
\cline { 2 - 6 } & test group & 23 & 79.357 & 7.537 & 2.322 & 0.024 \\
\cline { 2 - 5 } & Group & 23 & 71.332 & 6.332 & & \\
\hline \multirow{2}{*}{$\begin{array}{l}\text { Low } \\
\text { group }\end{array}$} & test group & 23 & 58.773 & 5.217 & 3.102 & 0.000 \\
\cline { 2 - 5 } & Group & 23 & 43.310 & 5.394 & & \\
\hline
\end{tabular}

\section{Research Conclusion}

Through this experiment, we can draw the same conclusion earlier. That multivariate feedback can significantly improve the English writing self-efficacy, embodied in the following aspects:

Multi-feedback creates a writing atmosphere. Because it is the interaction and communication between peers, therefore, peer review can increase opportunities for cooperation, increase mutual trust and intimacy, mutual discovery and solve problems during the recommendation a good friendship and partnership. Such learning atmosphere can be further harmony and rapport, learners are also more willing to accept the proposal and evaluation of comments [7]. And peer review can eliminate students 'fear of difficulty in English writing to improve students' self-confidence, reduce anxiety because of fault generated and tension.

Multi-feedback feedback changes bring success. Because of the way the content and evaluation criteria for the evaluation of the more detailed and clear, so that those with lower levels of writing students have higher self-efficacy. Clear positioning of their strengths and weaknesses, so as to formulate a more detailed study and improvement program.

For the above findings, the teacher can be extracted from the feedback correction current teaching practices. Such as teachers should be individualized, flexible use of various feedback teaching [8]; In addition, students feel the same feedback for the reaction effect more obvious, so the teacher should increase the intensity of peer feedback, and according to the level of students' writing to complement feedback.

\section{Conclusion}

This article has discussed the traditional teacher feedback and peer feedback formed experimentally controlled empirical study of the impact made by multivariate feedback right. Given the multi-feedback can enhance a sense of self-efficacy in College English Writing better than traditional single teacher feedback. Therefore, the classroom teaching should actively introduce peer review and other means of feedback and makes it varied, It also choose the right student feedback and evaluation mechanisms [9] according to the specific circumstances of the students, their English writing maximize their potential and improve their English literacy.

\section{Acknowledgements}

Fund Project: Department of Education Research Project of Shaanxi Province, The Empirical Study on the Effect of Multi-Feedback on Self-Efficacy Sense of College English Writing

Item Number: 16JK2069

\section{References}

[1] Wu Yuhong. Review on self-efficacy - An Empirical Study Based on College English Writing [J]. Foreign Languages Teaching, 2013 (6): 68-72.

[2] Rollinson, P. Using peer feedback in the ESL writingclass [J]. ELT Journal, 2005,59 (1): 23 - 30.

[3] Xia Tianqiong. Affect self-efficacy and writing performance [J]. Formative Assessment on College English Writing Anhui University of Technology: Social Sciences, 2014 (4): 77-79.

[4] Li Hang, Liu Rude. Students Foreign Language Writing Anxiety Writing Self - Efficacy and prediction of writing performance [J]. Foreign Languages Research, 2013 (02): 48-54. 
[5] Tang Fang, Xu Jinfen. Survey and Research [J]. college English writing foreign language, 2011 (06): 22-29.

[6] Feng Jiayao. Empirical research in process genre approach self-efficacy for English Majors' Writing Ability [D]. Shenyang Normal University, 2014.

[7] Wang, S. \& P. Wu. The role of feedback and self-efficacy on web-based learning: The social cognitive perspective [J]. Computers \& Education, 2008, (51): 1589 -1598.

[8] Qian Suning. An Empirical Study of College English Writing Peer feedback effect of teaching [D]. Nanjing University, 2012.

[9] Lv Sha. Content based on education philosophy under the guidance of College Students' Autonomous learning and self-efficacy of empirical research [D]. North University of China, 2014. 